\title{
Freezing effect on the oleuropein content of olive leaves extracts obtained from microwave-assisted extraction
}

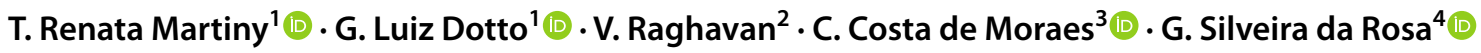

Received: 25 December 2020 / Revised: 12 August 2021 / Accepted: 8 October 2021 / Published online: 16 October 2021

(C) Islamic Azad University (IAU) 2021

\begin{abstract}
This work aimed to investigate the effect of freezing on the oleuropein content obtained from olive leaves extracts. The extracts were obtained by microwave-assisted extraction using different solvents, $\mathrm{pH}$, temperatures and microwave irradiation time. Afterward, HPLC was used to identify and quantify the amount of oleuropein in the extracts. A part of the extracts was immediately analyzed, and another was frozen for a week. The experimental results highlighted that the storage condition has a significant $(p<0.05)$ effect on the oleuropein content. Regardless of the extraction condition, the frozen storage was responsible for a decrease in the oleuropein content, ranging from 5.38 to $70.09 \%$. These results indicate that it is important to consider the degradation of oleuropein in frozen olive leaf extracts so that subsequent applications are suitable.
\end{abstract}

Keywords Phenolic compounds · Olive by-product · Olive tree residues · Olea europaea L. · Bioactive compounds · Frozen storage

\section{Introduction}

The olive tree is a fruit plant, scientific name Olea europaea L., family Oleaceae. Olive tree plantations exist throughout the world, making up areas of the order of millions of hectares, of which $90 \%$ are located on the coast of the Mediterranean Sea. In Brazil, the cultivation of olive trees has been growing (Coutinho et al. 2009; Cavalheiro et al. 2015). This demonstrates the social and economic importance of this crop and the possible benefits of using any of its by-products. From an economic point of view,

Editorial responsibility: Zhenyao Shen.

G. Silveira da Rosa

gabrielarosa@unipampa.edu.br

1 Department of Chemical Engineering, Federal University of Santa Maria, Santa Maria, Rio Grande Do Sul 97105-900, Brazil

2 Department of Bioresource Engineering, McGill University, 21111 Lakeshore Road, Ste-Anne-de-Bellevue, QC H9X 3V9, Canada

3 Department of Food Engineering, Federal University of Pampa, Maria Anunciação Gomes de Godoy Avenue, Bagé, Rio Grande do Sul 1650, Brazil

4 Department of Chemical Engineering, Federal University of Pampa, Unipampa, 1650, Maria Anunciação Gomes de Godoy Avenue, Bagé, Rio Grande do Sul, Brazil the interest for olive trees is linked to the production of olives and olive oil, but during this production, by-products are generated, equally valuable, in liquid and solid fractions, the solid fractions are the leaves and pomace and the liquid fraction is the mill wastewater, which can be valued composing innovative products, considered to be a rich source of natural products such as high phenolic compounds, in addition, the reuse of by-products reduces the pollution caused by them, as well as making olive mill plants more sustainable (Elkacmi et al. 2016, 2017; Nunes et al. 2016).

Among these by-products stand out the olive leaves. Historically, olive leaves are used for medicinal purposes, such as fighting fevers; in addition, they are known to possess compounds with bioactive potential (Benavente-García et al. 2000; Wichers et al. 2000). The leaves of this plant are considered a by-product generated in large quantity, about $25 \mathrm{~kg}$ of leaves and branches, per tree, from the pruning activities; however, the amount of pruning leaves can vary as it depends on some factors, such as the pruning method and weather conditions (Lamprou et al. 2020). In the olive oil plant, the leaves are separated from the olives by a blowing machine and can represent between 4 and $10 \%$ by weight of the olive that goes into processing. Only in Spain, 0.2 million tons of olive leaves are generated per year (Romero et al. 2018; Selin et al. 2018; Lama-Muñoz et al. 2019). Therefore, the investigation on the use of olive leaves and their extracts, in the most diverse industrial sectors, is 
relevant. Some of its applications include the development of natural drugs, functional foods and natural food preservatives (Ahmad-Qasem et al. 2016; Martiny et al. 2020a, b). The olive leaves have in their composition oleuropein as a major phenolic compound (Wichers et al. 2000; Guinda et al. 2004). There have been many publications on the activity properties of this compound. Researchers have studied its antioxidant activity (Lee and Lee 2010) and antimicrobial activity (Sudjana et al. 2009), thus showing the potential application of oleuropein as an alternative to chemical preservatives and antibiotics. In a recent research about solutions to eliminate the COVID-19 pandemic, the oleuropein contained in olive leaves was cited. Oleuropein have been powerful inhibitor to viruses and blocking the synthesis of enzymes for virus replication (Sun and Ostrikov 2020).

There are several methods related to the extraction operation of bioactive compounds from plant materials, but each has its advantages and disadvantages. Extraction processes are required that combine reasonable energy expenditure requirements with short times and reduced use of solvents, as well as the choice of non-toxic solvents, maintaining the efficiency of conventional solid-liquid extractions, such as maceration (Meullemiestre et al. 2016; da Rosa et al. 2019; Kırbaşlar and Şahin 2021). Thus, unconventional extraction techniques such as microwaveassisted extraction, ultrasound-assisted extraction and extraction using supercritical fluid are being applied to obtain valuable bioactive compounds from natural matrices (Otero et al. 2020). Among these techniques, microwave-assisted extraction is promising and was chosen in this study. This technique uses less solvent, has a low extraction cost and, as the main advantage, reduces extraction time (Otero et al. 2020; Rosa et al. 2021).

In industry, depending on the application, the degradation of oleuropein may be a desirable or undesirable reaction (De Leonardis et al. 2015). In most cases, plant preparations are marketed as liquid extracts or as powders resulting from drying (Souza et al. 2008; Ahmad-Qasem et al. 2016). However, it has been reported that drying may affect the activity and stability of bioactive compounds due to the losses caused by volatilization and decomposition (Faustino et al. 2007; Dorta et al. 2012). The knowledge regarding the changes caused by the freezing of plant extracts is of extreme importance for subsequent use of the extract or freeze-drying. These considerations justify the investigation of the oleuropein content in olive leaf extract and its stability after frozen storage. The aim of this work was to investigate the effect of freezing on the oleuropein content from olive leaves extracts obtained by microwave-assisted extraction. This work was developed in March 2019 in the Department of Bioresource Engineering located on the Macdonald Campus of McGill University.

\section{Materials and methods}

\section{Raw material}

The olive leaves (Fig. 1)-type Arbequina were collected in Pinheiro Machado, Brazil ( $\left.31^{\circ} 30^{\prime} 04.0^{\prime \prime} \mathrm{S}, 53^{\circ} 30^{\prime} 42.0^{\prime \prime} \mathrm{W}\right)$. The leaves were washed in running water, dipped in a $2 \%$ sodium hypochlorite solution and rinsed in sterilized water. The leaves were oven dried (ETHIK, Brazil) at $40{ }^{\circ} \mathrm{C}$ for $24 \mathrm{~h}$. The leaves were milled (IKA ${ }^{\circledR}$ A11BS32, China) and sieved (Bertel, Brazil) to select particles lower than $0.272 \mathrm{~mm}$.

\section{Extraction process}

In order to obtain olive leaf extracts (OLE), microwave-assisted extraction was performed in a multi-mode microwave-assisted unit (SCP Science, Canada) at $2.45 \mathrm{GHz}$ and $1000 \mathrm{~W}$. The
Fig. 1 Experimental flow illustration

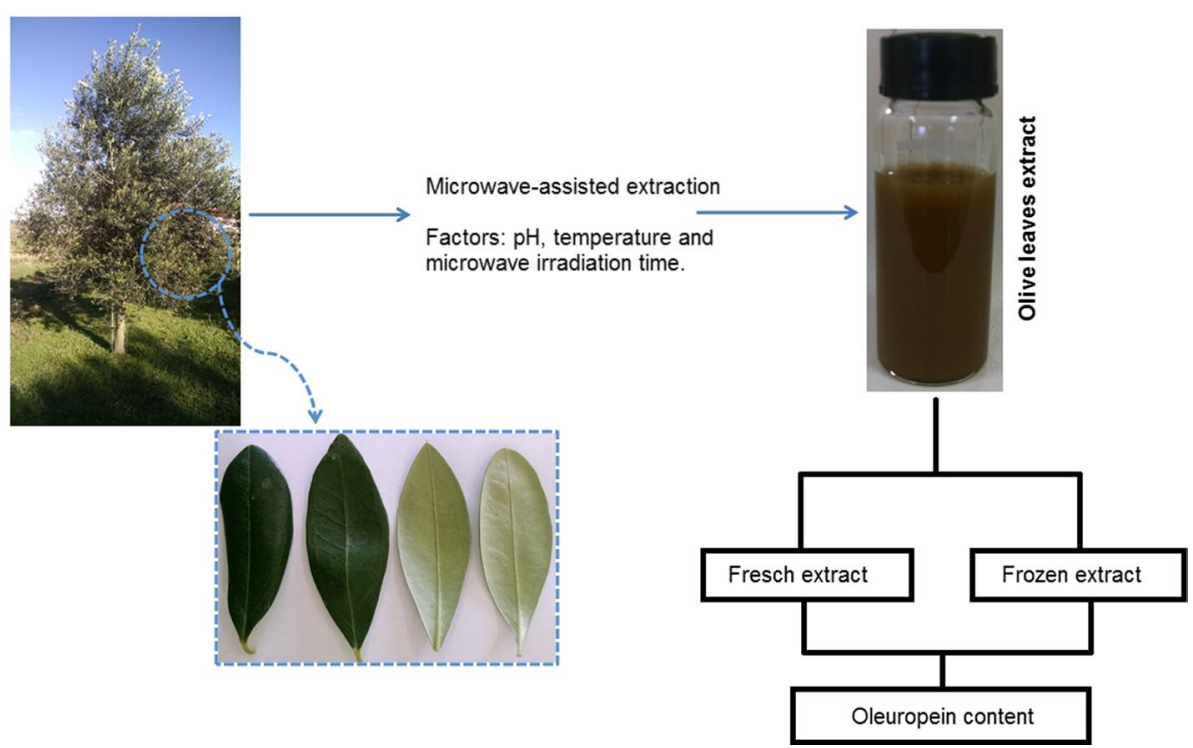


extraction was carried out with $0.5 \mathrm{~g}$ of milled material in $25 \mathrm{~mL}$ of distilled water (da Rosa et al. 2019). Different irradiation times, $\mathrm{pH}$ and temperatures were tested (Table 1). To cover a wide range of parameters, a full factorial design $2^{3}$ was developed with three repetitions at the central point. After extraction, the extracts were subjected to vacuum filtration using Whatman 4 filter paper (Sigma-Aldrich, USA). One part of the extracts was frozen at $-20^{\circ} \mathrm{C}$ for a week, and the other part was immediately characterized. The extracts that were not frozen were named fresh extracts (FRESH.E). Figure 1 summarizes the flow of the methodology used.

\section{Oleuropein quantification}

The quantitative analyses of oleuropein in OLE were performed by high-performance liquid chromatography_HPLC (Agilent 1100 series instrument, USA), analogously to the methods used by Ansari et al. (2011) and da Rosa et al. (2019). Oleuropein were separated on a reversed phase Discovery column (Supelco, USA) RP C18 ( $5 \mu \mathrm{m}, 25 \mathrm{~cm} \times 4.6 \mathrm{~mm})$, fitted with a Supelguard cartridge (Discovery, USA), C18 $(5 \mu \mathrm{m}, 2 \mathrm{~cm} \times 4 \mathrm{~mm})$ and then analyzed using a variable wavelength detector (VWD) that was set at $280 \mathrm{~nm}$. The mobile phase was a mixture of water, acetonitrile and acetic acid $(80 / 19 / 1 \mathrm{v} / \mathrm{v} / \mathrm{v})$. The OLE was filtered through a $0.45-\mathrm{mm}$ syringe filter and directly injected in the HPLC. The column temperature was maintained at $25^{\circ} \mathrm{C}$, and the mobile flow rate was fixed at $1.0 \mathrm{~mL} \mathrm{~min}^{-1}$. The oleuropein was identified and quantified using external standards and a calibration curve. The oleuropein content was expressed in $\mathrm{mg}$ $\mathrm{g}^{-1}$ olive leaves (dry basis, d.b.). All samples were analyzed in triplicate.

\section{Statistical analysis}

Experimental data were expressed as mean \pm standard deviation. Significant differences among the means were determined by Tukey test at $p<0.05$ by Statistica software (StatSoft Inc., 10, Tulsa, OK, USA).

\section{Results and discussion}

Table 1 shows the results for oleuropein content of the extracts. The FRESH.E were evaluated for oleuropein ranging from 9.021 to $15.607 \mathrm{mg} \mathrm{g}^{-1}$ (d.b.). The frozen extracts (FROZEN.E) ranging from 4.381 to $13.220 \mathrm{mg} \mathrm{g}^{-1}$ (d.b.). A good reproducibility of the extraction process was verified through the results obtained by experiments 9 to 11 , which correspond to the central points.

The extraction of oleuropein is the target of many studies; however, its storage and stability were also discussed. To determine the overall value of the extraction method used, the maximum yield of oleuropein from the extract was compared with data for oleuropein from other studies in the literature (Table 2). Here, the maximum oleuropein content obtained in this study using microwaves are among the highest extraction yields. These comparisons included the conventional extraction technique (maceration). The results of this work are comparable to those found in the literature. It is worth mentioning that important differences are observed, such as the type of solvent, extraction technique, and origin of the plant matrix.

Generally, extraction of bioactive compounds of olive leaves requires suitable solvents, such as ethanol, as shown in the referenced literature; however, they have a negative impact on the environmental and also on cost, safety and health; therefore,
Table 1 Oleuropein content of extracts obtained from microwave-assisted extraction

\begin{tabular}{llllccc}
\hline $\begin{array}{l}\text { Extraction } \\
\text { condition }\end{array}$ & $\begin{array}{l}\text { Irradiation } \\
\text { time }(\mathrm{min})\end{array}$ & $\mathrm{pH}$ & $T\left({ }^{\circ} \mathrm{C}\right)$ & $\begin{array}{l}\text { Oleuropein content of } \\
\text { fresh extract }\left(\mathrm{mg} \mathrm{g}^{-1}\right)\end{array}$ & $\begin{array}{l}\text { Oleuropein content of } \\
\text { frozen extract }\left(\mathrm{mg} \mathrm{g}^{-1}\right)\end{array}$ & $\begin{array}{l}\text { Loss in oleuro- } \\
\text { pein content }(\%)\end{array}$ \\
\hline 1 & 2 & 3 & 60 & $10.401 \pm 0.094^{\mathrm{a}}$ & $7.895 \pm 0.113^{\mathrm{b}}$ & 24.10 \\
2 & 6 & 3 & 60 & $13.738 \pm 0.001^{\mathrm{a}}$ & $8.826 \pm 0.043^{\mathrm{b}}$ & 35.76 \\
3 & 2 & 9 & 60 & $9.980 \pm 0.062^{\mathrm{a}}$ & $8.810 \pm 5.243^{\mathrm{a}}$ & 11.73 \\
4 & 6 & 9 & 60 & $15.607 \pm 0.002^{\mathrm{a}}$ & $4.668 \pm 0.007^{\mathrm{b}}$ & 70.09 \\
5 & 2 & 3 & 100 & $12.832 \pm 0.004^{\mathrm{a}}$ & $12.140 \pm 0.026^{\mathrm{b}}$ & 5.38 \\
6 & 6 & 3 & 100 & $9.021 \pm 0.003^{\mathrm{a}}$ & $5.933 \pm 0.008^{\mathrm{b}}$ & 34.23 \\
7 & 2 & 9 & 100 & $14.886 \pm 0.025^{\mathrm{a}}$ & $13.220 \pm 0.262^{\mathrm{b}}$ & 11.22 \\
8 & 6 & 9 & 100 & $10.090 \pm 0.0003^{\mathrm{a}}$ & $10.820 \pm 0.048^{\mathrm{a}}$ & - \\
9 & 4 & 6 & 80 & $12.871 \pm 0.003^{\mathrm{a}}$ & $7.144 \pm 0.092^{\mathrm{b}}$ & 44.73 \\
10 & 4 & 6 & 80 & $12.797 \pm 0.004^{\mathrm{a}}$ & $6.362 \pm 0.172^{\mathrm{b}}$ & 50.29 \\
11 & 4 & 6 & 80 & $13.314 \pm 0.0035^{\mathrm{a}}$ & $4.381 \pm 0.005^{\mathrm{b}}$ & 67.10 \\
\hline
\end{tabular}

Each value is expressed as mean \pm standard deviation

Different letters in each extraction condition no. mean significant differences $(p<0.05)$ between fresh and frozen extracts (Tukey's test) 
Table 2 Review of oleuropein content from olive leaves reported according to different extraction methods

\begin{tabular}{llll}
\hline Extraction technique & Extraction solvent & $\begin{array}{l}\text { Oleuro- } \\
\text { pein content } \\
\left(\mathrm{mg} \mathrm{g}^{-1} \text { leaves }\right)\end{array}$ & References \\
\hline Microwave & Water & 15.607 & Present study \\
Microwave & Ethanol and water $(80: 20 \mathrm{v} / \mathrm{v})$ & 23 & Japón-Luján et al. (2006) \\
Microwave & Water & 14.468 & Rosa et al. (2021) \\
Microwave & Solvent-free/water as pre-treatment & 0.00006 & Sahin et al. (2017) \\
Maceration & Water & 2.65 & Khemakhem et al. (2017) \\
Maceration & Ethanol and water $(70: 30 \mathrm{v} / \mathrm{v})$ & 27.8 & Cifá et al. (2018) \\
Maceration & Methanol and water $(4: 1 \mathrm{v} / \mathrm{v})$ & 0.0432 & Jemai et al. (2008) \\
\hline
\end{tabular}

when the extracts are used in pharmaceuticals and food applications, the most recommended is water (Difonzo et al. 2017). Therefore, in the present research, only water was used as a solvent, which is a non-toxic solvent, so no extra steps are required for solvent removal, and even makes future applications of the extract safer, its include natural preservatives, microorganism inhibitor and to produce novel functional foods. In particular, oleuropein can be considered a functional food ingredient and a powerful inhibitor to viruses (van der Stelt et al. 2015; Sun and Ostrikov 2020).

In addition, using the microwave technique, extraction is faster, thus saving energy. It separates the solutes present in the active sites of plant matrices by increasing the temperature and pressure, followed by the diffusion of solvent through the solid sample and, finally, the release of the solutes in the solvent (Alupului et al. 2012). The maceration technique, for example, requires several hours of extraction to obtain regular yields. In this work, we successfully used a green extraction to obtain oleuropein.

The highest oleuropein content was obtained at the temperature of $60^{\circ} \mathrm{C}$, time of $6 \mathrm{~min}$ and $\mathrm{pH}$ 9. Ansari et al. (2011) extracted oleuropein with water at $60^{\circ} \mathrm{C}$ and obtained approximately $15 \mathrm{mg} \mathrm{g}^{-1}$ (d.b.), which corroborates with the result obtained in this study. The values obtained in our study were similar to those reported in the cited literature.

In all the extraction conditions, except extraction conditions 3 and 8 , there was a statistically significant difference between the oleuropein means of the fresh extract (FRESH.E) and the frozen extract (FROZEN.E). In the analysis of oleuropein in FRESH.E, the highest oleuropein was obtained in the extraction condition 4 (irradiation time of $6 \mathrm{~min}, \mathrm{pH} 9$ and $60^{\circ} \mathrm{C}$ ), and the lowest OLE was in condition 6 (irradiation time of $6 \mathrm{~min}, \mathrm{pH}$ 3 and $100{ }^{\circ} \mathrm{C}$ ). Conversely, in the FROZEN.E, the highest oleuropein was obtained in the extraction condition 7 (irradiation time of $2 \mathrm{~min}$, $\mathrm{pH} 9$ and $100^{\circ} \mathrm{C}$ ), and the lowest oleuropein was in condition 11 .

In all the extraction conditions studied, except extraction condition 8, there was a decrease in oleuropein (Fig. 2) after freezing. These results indicate that the freezing caused a degradation of the oleuropein initially present in the extract. Oleuropein hydrolyzes during storage. Hydroxytyrosol is a breakdown product of oleuropein, which is also a phenolic compound abundant in olive products (Lozano-Sánchez et al. 2013; Crawford et al. 2020). The significant reduction of oleuropein may be related to the unfrozen water fractions (Augusto et al. 2018). The enzymatic reactions are slow in frozen products; however, they are not completely blocked (Attrey 2017). The highest loss of oleuropein was $70.09 \%$.

In addition to freezing, the drying operation is a technique used for the preservation of bioactive compounds from olive leaves in storage. Selin et al. (2018) evaluated the oleuropein content of olive leaves after the drying operation and reported a significant decrease in the oleuropein content using oven-drying (38\%) and ambient air-drying (57\%) methods. De Leonardis et al. (2015) also showed a decrease in oleuropein in the storage condition studied by drying, and oleuropein was reduced of about $37 \%$. In contrast, De Castro and Capote (2010) observed a small loss $(0.46 \%)$ of oleuropein in the olive leaves storage by freezing. The results of the present study, added to the scientific evidence reported in the literature, indicate that for olive leaves, freezing storage is the best option, given that the losses in oleuropein content are smaller.

In any case, when freezing the extracts of olive leaves, the differences between FRESH.E and FROZEN.E should be considered significant and should not be ignored. Therefore, for the application of industrial freezing of olive leaf extracts or for their freeze drying, it would be more advisable to conduct the process with the microwave irradiation time of $2 \mathrm{~min}$, the solvent $\mathrm{pH} 3$ and the temperature at $100{ }^{\circ} \mathrm{C}$. Under these conditions, the amount of oleuropein was high and the loss of oleuropein is lower, only $5.38 \%$.

As mentioned, olive leaf extract can have several applications and much research has proven this. In a recent one, the researchers (Martiny et al. 2020b) produced olive leaf extract by microwave-assisted extraction $\left(\mathrm{pH}=6 ; \mathrm{T}=100{ }^{\circ} \mathrm{C} ; 2 \mathrm{~min}\right)$; as a result, they found the oleuropein content of $11.59 \mathrm{mg} \mathrm{g}^{-1}$, a value similar to those found in the present study. The authors applied olive leaf extract as a preservative in the production of active biodegradable packaging and managed to decrease microorganisms when they packed lamb meat (Martiny et al. 2020b). 

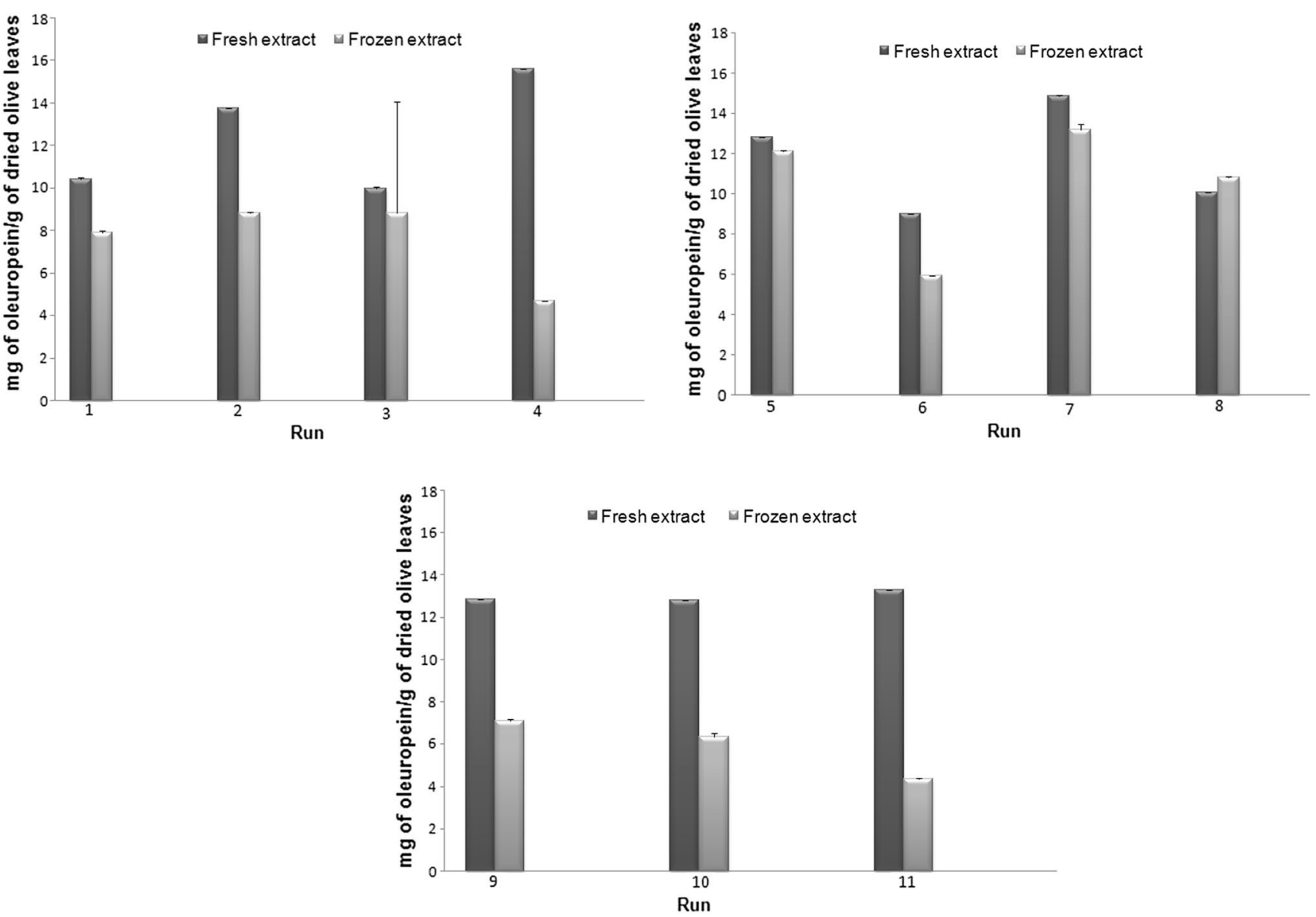

Fig. 2 Oleuropein content of extracts obtained from microwave-assisted extraction. Each value is expressed as mean \pm standard deviation

In another publication, the researchers applied olive leaf extract to control the oxidative stability of soybean oil, which resulted in greater antioxidant activity (Mohammadi et al. 2016).

\section{Conclusion}

Although there are many researches on the separation of olive biophenols, particularly oleuropein from olive leaves, there is little or no information about storage methods in order to preserve its composition. In this study, a simple environment-friendly method of extraction based on water by microwave-assisted irradiation to extract the oleuropein from the olive leaves. Analyses of the olive leaves extracts determined not only the content of oleuropein, but also their alteration after freezing. Freezing resulted in a reduction in oleuropein content. The extracted oleuropein contents ranged from 9.021 to $15.607 \mathrm{mg} \mathrm{g}^{-1}$, and postfreezing losses peaked at $70.09 \%$. Significant differences were found among the treatments tested. The study revealed that the oleuropein content of olive leaf extracts cannot be considered stable after freezing, so the use of this extract should take into account the losses it provides.
Acknowledgements The authors would like to thank the Coordination for the Improvement of Higher Education Personnel (CAPES) and the Natural Sciences and Engineering Research Council of Canada (NSERC) for their financial support.

Author contributions Thamiris Renata Martiny was involved in conceptualization, methodology, formal analysis, investigation, and writing — original draft. Guilherme Luiz Dotto was involved in supervision, resources, investigation, and writing - review \& editing. Vijaya Raghavan was involved in supervision, resources, investigation, and writing-review \& editing. Caroline costa de moraes was involved in conceptualization, resources, investigation, and writing - review \& editing. Gabriela Silveira da Rosa was involved in conceptualization, supervision, resources, investigation, and writing - review \& editing.

Funding Research Support Foundation of the Coordination for the Improvement of Higher Education Personnel (CAPES) (PGCI88887.125421/201600) and the Natural Sciences and Engineering Research Council of Canada (NSERC) (Discovery Grant) for their financial support.

\section{Declarations}

Conflict of interest The authors declare that they have no known competing financial interests or personal relationships that could have appeared to influence the work reported in this paper. 


\section{References}

Ahmad-Qasem MH, Ahmad-Qasem BH, Barrajón-Catalán E et al (2016) Drying and storage of olive leaf extracts. influence on polyphenols stability. Ind Crops Prod 79:232-239. https://doi.org/10.1016/j.inder op.2015.11.006

Alupului A, Călinescu I, Lavric V (2012) Microwave extraction of active principles from medicinal plants. UPB Sci Bull Ser B Chem Mater Sci 74:129-142

Ansari M, Kazemipour M, Fathi S (2011) Development of a simple green extraction procedure and HPLC method for determination of oleuropein in olive leaf extract applied to a multi-source comparative study. J Iran Chem Soc 8:38-47

Attrey DP (2017) Chapter 44 - safety and quality of frozen foods. Elsevier Augusto PED, Soares BMC, Castanha N (2018) Conventional technologies of food preservation. Elsevier

Benavente-García O, Castillo J, Lorente J et al (2000) Antioxidant activity of phenolics extracted from Olea europaea L. leaves. Food Chem 68:457-462. https://doi.org/10.1016/S0308-8146(99)00221-6

Cavalheiro CV, Picoloto RS, Cichoski AJ et al (2015) Olive leaves offer more than phenolic compounds - Fatty acids and mineral composition of varieties from Southern Brazil. Ind Crops Prod 71:122-127. https:// doi.org/10.1016/j.indcrop.2015.03.054

Coutinho EF, Ribeiro FC, Cappellaro TH, Araújo FA (2009) Mercados e comercialização. In: Coutinho EF, Ribeiro FC, Cappellaro TH (eds) Cultivo de oliveira (Olea europaea L.). Embrapa Clima Temperado, Pelotas, pp 102-115

Crawford LM, Janovick JL, Carrasquilla-Garcia N et al (2020) Comparison of DNA analysis, targeted metabolite profiling, and non-targeted NMR fingerprinting for differentiating cultivars of processed olives. Food Control. https://doi.org/10.1016/j.foodcont.2020.107264

da Rosa GS, Vanga SK, Gariepy Y, Raghavan V (2019) Comparison of microwave, ultrasonic and conventional techniques for extraction of bioactive compounds from olive leaves (Olea europaea L.). Innov Food Sci Emerg Technol 58:102234. https://doi.org/10.1016/j.ifset. 2019.102234

De Castro MDL, Capote FP (2010) Extraction of oleuropein and related phenols from olive leaves and branches. Elsevier Inc

De Leonardis A, Macciola V, Cuomo F, Lopez F (2015) Evidence of oleuropein degradation by olive leaf protein extract. Food Chem 175:568-574. https://doi.org/10.1016/j.foodchem.2014.12.016

Difonzo G, Russo A, Trani A et al (2017) Green extracts from Coratina olive cultivar leaves: antioxidant characterization and biological activity. J Funct Foods 31:63-70. https://doi.org/10.1016/j.jff.2017.01.039

Dorta E, Lobo MG, González M (2012) Using drying treatments to stabilise mango peel and seed: Effect on antioxidant activity. LWT_-Food Sci Technol 45:261-268. https://doi.org/10.1016/j.1wt.2011.08.016

Elkacmi R, Boulmal N, Kamil N, Bennajah M (2017) Techno-economical evaluation of a new technique for olive mill wastewater treatment. Sustain Prod Consum 10:38-49. https://doi.org/10.1016/j.spc.2016. 12.004

Elkacmi R, Kamil N, Boulmal N, Bennajah M (2016) Experimental investigations of oleic acid separation from olive oil and olive mill wastewater: a comparative study. J Mater Environ Sci 7:1485-1494

Faustino JMF, Barroca MJ, Guiné RPF (2007) Study of the drying kinetics of green bell pepper and chemical characterization. Food Bioprod Process 85:163-170. https://doi.org/10.1205/fbp07009

Guinda Á, Albi T, Pérez-Camino MC, Lanzón A (2004) Supplementation of oils with oleanolic acid from the olive leaf (olea europaea). Eur J Lipid Sci Technol 106:22-26. https://doi.org/10.1002/ejlt.200300769

Kırbaşlar Şİ, Şahin S (2021) Recovery of bioactive ingredients from biowaste of olive tree (Olea europaea) using microwave-assisted extraction: a comparative study. Biomass Convers Biorefin

Lama-Muñoz A, Del Mar CM, Espínola F et al (2019) Optimization of oleuropein and luteolin-7-o-glucoside extraction from olive leaves by ultrasound-assisted technology. Energies. https://doi.org/10.3390/ en12132486

Lamprou GK, Vlysidis A, Tzathas K, Vlyssides AG (2020) Statistical optimization and kinetic analysis of the extraction of phenolic compounds from olive leaves. J Chem Technol Biotechnol 95:457-465. https://doi. org/10.1002/jctb.6049

Lee OH, Lee BY (2010) Antioxidant and antimicrobial activities of individual and combined phenolics in Olea europaea leaf extract. Bioresour Technol 101:3751-3754. https://doi.org/10.1016/j.biortech.2009. 12.052

Lozano-Sánchez J, Bendini A, Quirantes-Piné R et al (2013) Monitoring the bioactive compounds status of extra-virgin olive oil and storage by-products over the shelf life. Food Control 30:606-615. https://doi. org/10.1016/j.foodcont.2012.06.036

Martiny TR, Pacheco BS, Pereira CMP et al (2020a) A novel biodegradable film based on $\kappa$-carrageenan activated with olive leaves extract. Food Sci Nutr 8:3147-3156. https://doi.org/10.1002/fsn3.1554

Martiny TR, Raghavan V, de Moraes CC et al (2020b) Bio-based active packaging: carrageenan film with olive leaf extract for lamb meat preservation. Foods 9:1759. https://doi.org/10.3390/foods9121759

Meullemiestre A, Petitcolas E, Maache-rezzoug Z et al (2016) Ultrasonics Sonochemistry Impact of ultrasound on solid-liquid extraction of phenolic compounds from maritime pine sawdust waste. Kinet, Optim Large Scale Exp 28:230-239. https://doi.org/10.1016/j.ultso nch.2015.07.022

Mohammadi A, Jafari S, Esfanjani A, Akhavan S (2016) Application of nano-encapsulated olive leaf extract in controlling the oxidative stability of soybean oil. Food Chem. https://doi.org/10.1016/j.foodchem. 2015.05.115

Nunes MA, Pimentel FB, Costa ASG et al (2016) Olive by-products for functional and food applications: Challenging opportunities to face environmental constraints. Innov Food Sci Emerg Technol 35:139148. https://doi.org/10.1016/j.ifset.2016.04.016

Otero DM, Oliveira FM, Lorini A et al (2020) Oleuropein: methods for extraction, purifying and applying. Rev Ceres 67:315-329. https:// doi.org/10.1590/0034-737X202067040009

Romero C, Medina E, Mateo MA, Brenes M (2018) New by-products rich in bioactive substances from the olive oil mill processing. J Sci Food Agric 98:225-230. https://doi.org/10.1002/jsfa.8460

da Rosa GS, Martiny TR, Dotto GL et al (2021) Eco-friendly extraction for the recovery of bioactive compounds from Brazilian olive leaves. Sustain Mater Technol 28:e00276. https://doi.org/10.1016/j.susmat. 2021.e00276

Selin Ş, Elhussein E, Bilgin M et al (2018) Effect of drying method on oleuropein, total phenolic content, flavonoid content, and antioxidant activity of olive (Olea europaea) leaf. J Food Process Preserv 42(5):e13604. https://doi.org/10.1111/jfpp.13604

Souza CRF, Schiavetto IA, Thomazini FCF, Oliveira WP (2008) Processing of Rosmarinus officinalis Linne extract on spray and spouted bed dryers. Braz J Chem Eng 25:59-69. https://doi.org/10.1590/S010466322008000100008

Sudjana AN, D'Orazio C, Ryan V et al (2009) Antimicrobial activity of commercial Olea europaea (olive) leaf extract. Int J Antimicrob Agents 33:461-463. https://doi.org/10.1016/j.ijantimicag.2008.10.026

Sun Z, Ostrikov K (Ken) (2020) Future antiviral surfaces : Lessons from COVID-19 pandemic. Sustain Mater Technol 25:e00203. https://doi. org/10.1016/j.susmat.2020.e00203

van der Stelt I, Hoek-van den Hil EF, Swarts HJM et al (2015) Nutraceutical oleuropein supplementation prevents high fat diet-induced adiposity in mice. J Funct Foods 14:702-715. https://doi.org/10.1016/j.jff.2015. 02.040

Wichers HJ, Soler-rivas C, Esp1 JC (2000) Review oleuropein and related compounds. J Sci Food Agric 80:1013-1023. https://doi.org/10.1002/ (SICI)1097-0010(20000515)80:7\%3c1013::AID-JSFA571\%3e3.0. $\mathrm{CO} ; 2-\mathrm{C}$ 